\title{
Scale Development, Validation and Use of Structural Equation Modelling to Test the Impact of Consumer Confidence and Persuasibility on Dissonance
}

\author{
*Sanjana Brijball Parumasur, Nabendra Parumasur \\ University of KwaZulu-Natal (Westville Campus), Durban, South Africa \\ *brijballs@ukzn.ac.za
}

\begin{abstract}
This study develops and validates a scale to assess the impact of consumer confidence and persuasibility on dissonance and applies the instrument to high-end consumers. It also assesses the relationship between consumer confidence and persuasibility as these constructs merge to influence dissonance. A sample of 200 new motor vehicle buyers who purchased from a leading and reputable motor vehicle company in KwaZulu-Natal, South Africa, was drawn using stratified random sampling based on range of motor vehicle (bottom, middle, top). Initially, exploratory factor analysis (EFA) was used to extract the factors. The reliability of the modified questionnaire was then assessed using Cronbach's Coefficient Alpha. Thereafter, confirmation factor analysis (CFA) was undertaken to develop and test the model structure in SEM, which generated a good model fit. Pearson $r$ was computed to assess the relationship amongst the dimensions. Using structural equation modelling, the results support a significant relationship between consumer persuasibility and dissonance and a significant but inverse relationship between consumer confidence and dissonance, and confidence and persuasibility respectively.
\end{abstract}

Keywords: Consumer persuasibility, consumer confidence, dissonance, scale development, structural equation modelling (SEM)

\section{Introduction}

One strategy to understand and predict consumption behaviour is to analyse the various needs, motivations and goals underlying pertinent action tendencies. Among the basic needs which may have a significant effect on consumer decision-making and behaviour is the need for cognitive consistency. ${ }^{1}$ When incongruent relations among cognitions or dissonance occurs it creates a noxious, psychologically uncomfortable state of disequilibrium, or tension/anxiety that demands reduction ${ }^{2}$ either by changing beliefs, attitudes, perceptions or perceptions of the action in order to restore internal harmony or balance ${ }^{3}$. Undoubtedly, whenever a consumer makes a decision, there exists some degree of cognitive dissonance which is particularly prevalent when the consumer has to choose among alternatives. When making choices, consumers often have difficulty determining the precise utilities of alternatives and are, therefore, uncertain about their preferences and this is exacerbated when the consumer is persuaded into the purchase or simply lacks confidence in the purchase. The consumer has doubts and anxieties about the choice made because the alternatives for egone had certain desirable traits, and the option selected has undesirable elements which the individual is forced to accept

\footnotetext{
${ }^{1}$ The cognitive interpreting process or desire for consistency was explored by Leon Festinger (1957) in the theory of cognitive dissonance and later revised by Elliot Aronson (1968) and the premise of the theory is that individual consumers strive toward consistency within the self. In Festinger's (1957) original formulation of dissonance theory, two elements in a cognitive system, be it a belief and an attitude, an attitude and a behaviour or a belief and behaviour, are consonant if they are in harmony with each other and dissonant if they are competing cognitions or in conflict with each other such that a discrepancy between the cognitions exist (George \& Edward, 2009; Kim, 2011; Nolan \& Nail, 2014; Petty, Unnave \& Strathman, 1991; Soutar \& Sweeney, 2003).

${ }^{2}$ Dissonance results in a noxious, psychologically uncomfortable state of disequilibrium, or tension/anxiety that demands reduction (Aronson, 1992; Elliot \& Devine, 1994; Engel \& Blackwell, 1982; Festinger, 1957; George \& Edward, 2009; Hoshino-Browne, 2012; Kassarjian \& Cohen, 1965; Keng \& Liao, 2009; Kim, 2011; Koller \& Salzberger, 2012; Sweeney, Hausknecht \& Soutar, 2000; Zajonc, 1960). ${ }^{3}$ Dissonance is a motivating or driving force to restore internal harmony, balance, consistency or congruity among opinions, attitudes and values (Festinger, 1957; Gawronski, 2012; Kim, 2011) by either changing beliefs, attitudes, perceptions or perceptions of the action (George \& Edward, 2009; Herman, 2006; Hoshino-Browne, 2012; Jarcho, Berkman \& Lieberman, 2011; Nolan \& Nail, 2014).
} 
with the choice, thereby adding an emotional perspective to dissonance ${ }^{4}$. Research indicates that numerous factors have the potential to trigger emotional and cognitive dissonance, such as, attractiveness of rejected alternative/s, degree of importance attached to a specific decision or product involvement (George \& Edward, 2009; Kim, 2011), importance of the choice to the individual's self-concept (Cummings \& Venkatesan, 1976; Kunreuther et al., 2002; Sweeney et al., 2000), number of negative characteristics in the chosen alternative, number of rejected alternatives, the degree of overlap between the available alternatives, time (Koller \& Salzberger, 2012; Markin, 1974), preference for consistency (Nolan \& Nail, 2014), threshold for dissonance (Soutar \& Sweeney, 2003; Sweeney et al., 2000) and consumer.

Persuasibility and confidence during the consumer decision-making process (Bell, 1967; Engel, 1963; Bearden, Hardesty \& Rose, 2001). The issue of consumer persuasibility and confidence during the purchase is particularly important because when consumers realise that they have been talked into buying a product that do not like, they will experience dissonance. Bell (1967) found no association between persuasibility and dissonance because the relationship was intercepted by consumer confidence. This study, therefore, aims to close this gap by developing and validating a scale to assess the impact of consumer persuasibility and consumer confidence or lack thereof on the prevalence and magnitude of dissonance amongst motor vehicle consumers. The purchase of a motor vehicle involves a large capital outlay and, therefore, demands extensive search, evaluation, involvement and hence, has the potential for emotional and cognitive dissonance. The study also assesses the relationship between consumer persuasibility and confidence as they merge to influence dissonance.

\section{Consumer persuasibility and consumer confidence or lack thereof and dissonance}

Consumers differ in their susceptibility to persuasion and those who are more easily persuaded are more likely to be highly dissonant after the purchase (Engel, 1963). For example, when a consumer realises that he/she was talked into buying a motor vehicle that he/she did not like, for a price that he/she did not want to pay, the customer is likely to experience dissonance. Therefore, Bell (1967) implies that all motor vehicle consumers may not be cognitively dissonant; instead, the amount of satisfaction a customer has with the motor vehicle purchased is a result of the individual's personality and experience when purchasing the new vehicle. However, Bell (1967) found no association between persuasibility or the degree to which the consumer is influenced by the salesperson and dissonance. The explanation for this result is that the customer's self-confidence influences persuasibility as well as dissonance. According to Stuart (1984), consumer confidence is the interplay of numerous attitudes and expectations and determines willingness to buy. Bearden, Hardesty \& Rose (2001) define consumer self-confidence as the degree to which a person feels capable and comfortable with regard to his/her own decisions and behaviours in the purchase environment. Bearden et al. (2001) distinguish between decision-making self-confidence and protection. The former relates to the consumer's ability to make effective decisions by obtaining and using information in the marketplace whilst protection refers to the customer's capability to protect him/herself from "business messages aimed at misleading, deceiving and treating customers unfairly" (Clark, Goldsmith \& Goldsmith, 2008).

Bearden et al. (2001) believe that self confidence may be specifically related to consumer information search. According to Loibl, Cho, Diekmann and Batte (2009), the behaviour of consumers is frequently influenced by their confidence which depends on their information search particularly in expensive purchases. Similarly, Reed, Mikels and Löckenhoff (2012) found that lower levels of self-efficacy may inhibit consumer willingness to evaluate multiple alternatives and to engage in extensive information search when undertaking complex decision making. Hence, consumers differ in the confidence needed to make a decision among alternatives and to choose the one that has the greatest potential to fulfil predetermined needs (Loibl et al., 2009). Simply put, decision-making self confidence refers to the consumer's ability to make proper judgements (Loibl et al., 2009). Bearden et al. (2001), Wells and Prensky (1996) and Loibl et al. (2009) also reported a positive relationship between high consumer confidence and high information strategy. However, Kiel and Layton (1981) reported an inverse relationship between buyer self confidence and search for information among

\footnotetext{
${ }^{4}$ Festinger (1957) conceptualized dissonance from a cognitive and emotional perspective because the dissonance experienced is painful (Koller \& Salzberger, 2012; Soutar and Sweeney, 2003; Sweeney et al., 2000).
} 
motor vehicle buyers maintaining that less confident buyers spend more time searching for information in attempts to overcome their lack of confidence with greater information search and evaluation.

In their multi-dimensional scale on dissonance, Sweeney et al. (2000) refers to one dimension as 'concern over the deal' and assesses the extent to which the consumer after the purchase believes that he/she may have been influenced against his/her own beliefs by the salesperson, thereby making persuasion a major influence on the extent of dissonance experienced. Research has also assessed susceptibility to persuasion based on the nature of the message and has concluded that two-sided messages are superior in terms of its cognitive effect on the recipient (consumer) as being provided with arguments in favour of and those opposing a proposition enables the recipient (consumer) to place higher confidence in the target (salesperson) resulting in greater trustworthiness and stronger positive attitudes towards the target (salesperson) (Crowley \& Hoyer, 1994). However, Sanaktekin and Sunar (2008) believed that the effectiveness of two-sided messages depended on how informed the recipients (consumers) were before the message. Hence, cognitive clarity is a major source of competitive advantage in any market (Walsh, HennigThurau \& Mitchell, 2007). Similarly, researchers deduced that a more persuasive approach is one that is balanced and reasonable instead of one that is overly forceful and one-sided (Nadeem, 2007; Stanchi, 2013). Similarly, Koller and Salzberger (2012) and Soutar and Sweeney (2003) found that if the salespersons appear too forceful or pushy, consumers may feel forced into a decision that they were not ready to make or that was made against their will. Tabor (2005), however, believes that the power of persuasion lies in creating the lethal combination of expertise, honesty and likeability, whether superficial/apparent or ernest.

Bell (1967) deduced that a consumer's self-confidence has an unusual effect on persuasibility. Those most confident and those least confident in their car buying ability are most difficult to persuade whilst those moderately confident are the easiest to persuade (Bell, 1967). Consumers who are high in self-confidence are difficult to influence because they have experience in making suitable decisions and have faith in their own judgement. Individuals low in self-confidence is difficult to persuade because their unstable self-esteem causes them to react defensively against any attempt of persuasion (Bell, 1967). Those with a moderate degree of self-confidence are most persuasible because they are not secure with their own judgement nor highly defensive. Bell (1967) studied the effects of the associations between self-confidence and persuasibility on a consumer's psychological reactions or cognitive dissonance after purchasing a new car. Significant relations between persuasibility and cognitive dissonance were observed only when the selfconfidence of the customer is controlled. Therefore, Bell (1967, p. 14-15) found:

- Customers, who are high on self-confidence, were high on dissonance if they were easily persuaded in buying their new cars, since being persuaded is contrary to their usual behaviour.

- Those who are high on self-confidence experienced very little dissonance; a finding supported in other contexts as well (Cheng \& Hsu, 2012). They made their choices, accepted them and were content with their decisions.

- Those low on self-confidence had little dissonance if they were readily persuaded. They were convinced by the salesperson that they had made the right choice and their confidence was enhanced by the persuasion attempts of the salesperson.

- Those with little confidence were highly dissonant if they resisted influence attempts by the salesperson and were not easily persuaded. After completing the purchases they began to have self-doubts.

Koller and Salzberger (2012) found that the enthusiasm for information enhances the confidence of the consumer in the purchase perhaps because they feel more informed or more competent to make the decision. In addition, more confident decision-makers rely less on decision aid (Whitecotton, 1996 cited in Woolley, 2007). Lee and Dry (2006) deduced that confidence is influenced both by frequency and accuracy of the advice. Bell (1967, p. 15) found a slightly curvilinear relationship between persuasibility and quality of service, the indirect cause of dissonance:

- Those who are low on persuasibility received quite good service. These individuals, referred to as 'grinders', were difficult to persuade and wore the salesperson down in their vigorous effort to obtain a good deal. They consequently, received very high quality services, often at good prices. 
- Those who are easily persuaded in their car purchases are called 'flakes'. Whilst salespersons make jokes about this type of customers, they feel sorry for them and are more likely to give them free accessories, services and special care upon delivery. 'Flakes' often get quite good service because they pay slightly more for their cars than do the 'grinders' (Bell, 1967, p. 15).

- Those medium on persuasibility get the worst service. They grind enough to put the salesperson on guard and to not feel sympathetic to the consumer and they do not have the talent or desire to wear down the salesperson to obtain good service (Bell, 1967).

Thus, persuasibility acts as an indirect cause of consumers' dissonance. Those who are moderately persuasible experience the worst service, and those who get poor service tend to be the highest on cognitive dissonance (Bell, 1967). It is evident that the type of personality an individual brings to the dealership and the experiences encountered whilst and after purchasing the new car determines the extent of dissatisfaction and cognitive dissonance. A potential cause for post-purchase dissonance is the quality of service received. Ehrlich, Guttman, Schonbach and Mills (1957) assumed that most people who purchase new cars will be dissonant, regardless of the quality of service received. However, Bell (1967) supports the relationship between respondent's cognitive dissonance and the perceived quality of service and concludes that the better the quality of service received, the lower the degree of consumer dissonance. Taking cognisance of the aforementioned, the following premises lay the foundation of this study:

- Consumer confidence is related to consumer information search and cognitive clarity.

- Susceptibility to persuasion depends on the individual's personality, experience and confidence in the purchase.

- The level of consumer confidence influences the individual's susceptibility to persuasion and hence, dissonance, especially if the consumer is dissatisfied with the service and product after the purchase.

\section{Methodology}

Subjects: A sample of 200 new motor vehicle buyers was drawn using the stratified random sampling technique. Only new motor vehicle buyers (within KwaZulu-Natal, South Africa) who concluded their purchases in one major, reputable and leading motor vehicle manufacturing company and who owned the vehicle for a maximum period of seven months were considered, so as to avoid cognitive intrusion. The sample may be described in terms of ranger of motor vehicle purchased, month of purchases, gender and age of buyer. Representativeness was achieved by drawing a proportional frequency of consumers in the different ranges of motor vehicles purchased. The motor vehicles purchased were divided on the basis of price into 'bottom of the range' (47.25\% of sample), 'middle of the range' (33.75\%) and 'top of the range' (19\%). The representation of male (47\%) and female (53\%) motor vehicle consumers were also ensured. In terms of age, the sample ranged from 20 to 65 years with a preponderance of candidates in the age group 30 to 39 years. Whilst the profile of the composition of the sample was presented in terms of these biographical characteristics, an analysis of them in terms of consumer confidence, persuasibility and dissonance did not fall within the jurisdiction of this study. The adequacy of the sample for Factor Analysis was determined on the basis of the Kaiser-Olkin Measure of Sampling Adequacy (0.938) and Bartlett's Test of Sphericity (4258.546; $p=0.000$ ), which respectively showed suitability and significance. The results indicate that the normality and homoscedasticity preconditions are satisfied.

Instruments: The measuring instrument was a self-developed, precoded, standardised questionnaire comprising of Sections A and B. Section A related to biographical data of the purchasers (age, gender), month of purchases and a motor vehicle specific variable, namely, range of vehicle (bottom, middle and top of range). Section B initially included 27 items which were measured using the Likert scale ranging from strongly disagree (1), disagree (2), neither agree nor disagree (3), agree (4) and strongly agree (5) as follows:

- Consumer persuasibility (5 items)

- Consumer confidence (7 items) - these were reverse (R) items and required that the scale be reversed when capturing

- Dissonance (15 items) 
Procedure: The mail survey was used and hence, the questionnaires were self-administered. The questionnaire, together with a covering letter indicating the purpose and need for the study, was posted to sample subjects using the postal services. Each respondent was contacted telephonically informing him/her of the arrival of the questionnaire, already posted. The questionnaires were numbered so as to follow up on non-responses. Those who did not respond within two weeks were again telephoned to remind them of the purpose of the study, so as to ensure a suitable response rate. A self-addressed envelope and stamp was provided so respondents need not bear a financial cost, thereby increasing the return rate.

Statistical Analysis: When designing the initial questionnaire, face and content validity was prioritised by including all aspects of persuasibility, confidence and dissonance that repeatedly surfaced when conducting the literature review. The validity of the questionnaire was statistically assessed using Exploratory Factor Analysis (EFA) to identify and extract the factors and Confirmatory Factor Analysis (CFA) to test the emerging model structure. The reliability of the modified questionnaire was statistically assessed using Cronbach's Coefficient Alpha. The overall final questionnaire reflected a very high level of inter-item consistency (Cronbach's Alpha $=0.934$ ). The results of the study were analysed using the Pearson Product Moment Correlation and structural equation modelling (SEM) using AMOS. SEM was used to assess the impact of consumer persuasibility and consumer confidence on dissonance experienced as well as the relationship between consumer persuasibility and consumer confidence. Hence, SEM was used to draw conclusions on the following hypotheses:

$\mathrm{H}_{1}$ : The higher the level of consumer persuasibility during the decision making process, the higher the level of dissonance experienced.

$\mathrm{H}_{2}$ : The higher the level of consumer confidence in the decision making process, the lower the degree of dissonance experienced.

$\mathrm{H}_{3}$ : Consumer confidence and consumer persuasibility are inversely related as they influence the magnitude of dissonance experienced.

\section{Results}

Measurement model and factor structure: The study assesses the impact of consumer persuasibility and consumer confidence on dissonance using a self-developed questionnaire comprising of these three constructs. Initially, consumer persuasibility comprised of 5 items, the consumer confidence dimension had 7 items, and dissonance comprised of 15 items. However, when structural equation modeling (SEM) was applied to these 27 initial items, it generated poor model fit indices. Hence, exploratory factor analysis with Kaiser's criterion and oblique (oblimin) rotation was conducted to assess how the key constructs cluster (Table 1).

Table 1: Exploratory Factor Analysis generating pattern matrix

\begin{tabular}{llll}
\hline Item Code & Component & $\mathbf{2}$ & $\mathbf{3}$ \\
\hline D7 & 0.697 & & \\
D8 & 0.688 & & \\
D5 & 0.686 & & \\
D6 & 0.658 & & \\
D10 & 0.625 & & \\
D11 & 0.604 & & \\
D15 & 0.549 & & \\
D9 & 0.547 & & \\
D13 & 0.486 & & \\
D12 & 0.348 & 0.867 & \\
C4 & & 0.790 & \\
C6 & & 0.554 & \\
C2 & & 0.499 & \\
C5 & & 0.476 & \\
C3 & & & \\
\hline
\end{tabular}




\begin{tabular}{lll}
\hline C1 & 0.395 & \\
D3 & & \\
D4 & & \\
D2 & 0.915 & \\
D1 & 0.605 & \\
P1 & 0.576 & -0.873 \\
P5 & & -0.847 \\
P4 & & -0.821 \\
P2 & & -0.696 \\
P3 & & -0.690 \\
D14 & & -0.496 \\
C7 & & -0.366 \\
\hline
\end{tabular}

From Table 1, it is evident that 6 items (D7, D8, D5, D6, D10 and D11) as highlighted under Factor 1 were included in the study. Items $<0.6$ were excluded since the factor initially had numerous (15) items. In addition, 4 of the initial dissonance items clustered together under Factor 3 (D1, D2, D3, D4) and 1 under Factor 4 (D14) since they specifically related to the performance of the motor vehicle and was thus, excluded from dissonance, whose items related directly to post-purchase regret. Hence, the 6 items selected in Factor 1 relate to dissonance. Five items in Factor 2 were included but the $6^{\text {th }}$ item (C1) was excluded as the item loading was too small $(0.348)$ and C7 was excluded as it loaded in Factor 4 and had a small item loading (0.366). Hence, the 5 items selected in Factor 2 relate to consumer confidence. The 5 items that loaded significantly in Factor 4 relate to persuasibility. The aforementioned Factors have eigenvalues $>1$ and account for $67.1 \%$ of the variance. The selected items, statements and their items loadings are presented in Table 2 .

Table 2: Selected Items, Statements and Item Loadings

\begin{tabular}{|c|c|c|c|}
\hline $\begin{array}{l}\text { Item } \\
\text { Code }\end{array}$ & $\begin{array}{l}\text { Statement }(D=\text { Dissonance, } \quad C=\text { Confidence, } P= \\
\text { Persuasibility) }\end{array}$ & $\begin{array}{l}\text { Item } \\
\text { Loading }\end{array}$ & Communalities \\
\hline D5 & The style of the car needs further improvement. & 0.686 & 0.548 \\
\hline D6 & The car is not as popular as I was initially given to understand. & 0.658 & 0.552 \\
\hline D7 & The vehicle lacks the roominess that I expected of it. & 0.697 & 0.475 \\
\hline D8 & Many aspects of the interior of the car need redesigning. & 0.688 & 0.561 \\
\hline D10 & I feel that the car that I bought does not satisfy my needs. & 0.625 & 0.749 \\
\hline D11 & $\begin{array}{l}\text { I wish I had selected an alternative make of car when I was } \\
\text { making my decision to purchase. }\end{array}$ & 0.604 & 0.762 \\
\hline $\mathrm{C} 2$ & $\begin{array}{l}\text { I felt I did not receive the same kind of deal that other purchasers } \\
\text { had received. }\end{array}$ & 0.554 & 0.634 \\
\hline C3 & $\begin{array}{l}\text { When choosing amongst the alternatives considered I often felt } \\
\text { insecure about my own judgment. }\end{array}$ & 0.476 & 0.566 \\
\hline $\mathrm{C} 4$ & $\begin{array}{l}\text { When making my decision, I was reluctant 'to wear the } \\
\text { salesperson down' in attempts to get a good deal. }\end{array}$ & 0.867 & 0.768 \\
\hline $\mathrm{C} 5$ & I feel I did not get a good deal. & 0.499 & 0.676 \\
\hline C6 & I lack the experience needed when selecting a car. & 0.790 & 0.644 \\
\hline P1 & I feel I have been talked into buying a car I do not like. & -0.873 & 0.829 \\
\hline $\mathrm{P} 2$ & $\begin{array}{l}\text { I feel I have been talked into buying a car for a price I did not } \\
\text { want to pay. }\end{array}$ & -0.696 & 0.685 \\
\hline P3 & I feel the salesperson imposed his/her views onto me. & -0.690 & 0.731 \\
\hline $\mathrm{P} 4$ & I feel the salesperson influenced my choice of color. & -0.821 & 0.610 \\
\hline P5 & I feel the salesperson influenced my choice of style of vehicle. & -0.847 & 0.769 \\
\hline
\end{tabular}

The final 16 item questionnaire, therefore, defined dissonance in terms of 6 items, consumer confidence using 5 items and persuasibility in terms of 5 items and the average communalities after extraction is 0.66 . The reliability of the questionnaire was then statistically assessed using Cronbach's Coefficient Alpha which generated a very high level of inter-item consistency for the questionnaire $(\alpha=0.934)$. The reliabilities for 
the dimensions of consumer confidence $(\alpha=0.856)$, dissonance $(\alpha=0.863)$, and persuasibility $(\alpha=0.908)$ reflect very high levels of inter-item consistency and reliability. Thereafter, confirmatory factor analysis (CFA) was undertaken to develop the model structure in SEM. Model identification was attained, and the indices for global fit reflects that the model sufficiently represented the data with CMIN $/ \mathrm{DF}=1.831, \mathrm{GFI}=0.9$, RMSEA $=0.065$ and a comparative fit (CFI) of 0.960 . CMIN/DF should ideally be 2 or less than 2 (Ullman, 2001) to reflect a good fit, GFI should be $>0.9$ (Byrne, 1994), RMS or RMSEA should be $<0.08$ (Browne \& Cudeck, 1993) but should not exceed 0.08 (Hu \& Bentler, 1999) and CFI should exceed 0.93 (Byrne, 1994). Bollen (1989) emphasizes that these criteria simply serve as guidelines. Hence, the model adequately represents the input data particularly taking cognisance of the large sample of 200 motor vehicle consumers being studied.

Structural model: It was hypothesised that:

$\mathrm{H}_{1}$ : The higher the level of consumer persuasibility during the decision making process, the higher the level of dissonance experienced.

$\mathrm{H}_{2}$ : The higher the level of consumer confidence in the decision making process, the lower the degree of dissonance experienced.

$\mathrm{H}_{3}$ : Consumer confidence and consumer persuasibility are inversely related as they influence the magnitude of dissonance experienced.

Correlations between the constructs are reflected in Table 2 .

Table 2: Pearson Correlations of the dimensions

\begin{tabular}{llll}
\hline Dimension & $\begin{array}{l}\text { Consumer } \\
\text { Persuasibility }\end{array}$ & $\begin{array}{l}\text { Consumer } \\
\text { Confidence }\end{array}$ & Dissonance \\
\hline Consumer Persuasibility & 1.000 & & \\
Consumer Confidence & $-0.790^{*}$ & 1.000 & \\
Dissonance & $0.41^{*}$ & $-0.47^{*}$ & 1.000 \\
\hline
\end{tabular}

$* \mathrm{p}<0.01$

Table 2 reflects that there is a significant relationship between consumer persuasibility and dissonance at the $5 \%$ level of significance. Furthermore, there is a significant but inverse relationship between consumer persuasibility and consumer confidence and between consumer confidence and dissonance respectively at the $5 \%$ level of significance. The relationship between consumer confidence and persuasibility are strong, whilst the relationships between consumer persuasibility and dissonance and, consumer confidence and dissonance are moderate. The structural model of the impact of consumer confidence and consumer persuasibility and perceived dissonance was tested by performing SEM analyses using AMOS. The structural model, as depicted in Figure 1, evaluated the hypothesised regressions. The hypothesised model, as depicted in Figure 1, provided a good fit to the data which indicated that the model represents the data well with $\mathrm{CMIN} / \mathrm{DF}=1.831, \mathrm{RMR}=0.34, \mathrm{GFI}=0.9, \mathrm{RMSEA}=0.065$, a comparative fit of CFI $=0.96$ and TLI of 0.951 .

Figure 1: Maximum Likelihood Regression (MLR) Estimates for the hypothesized model

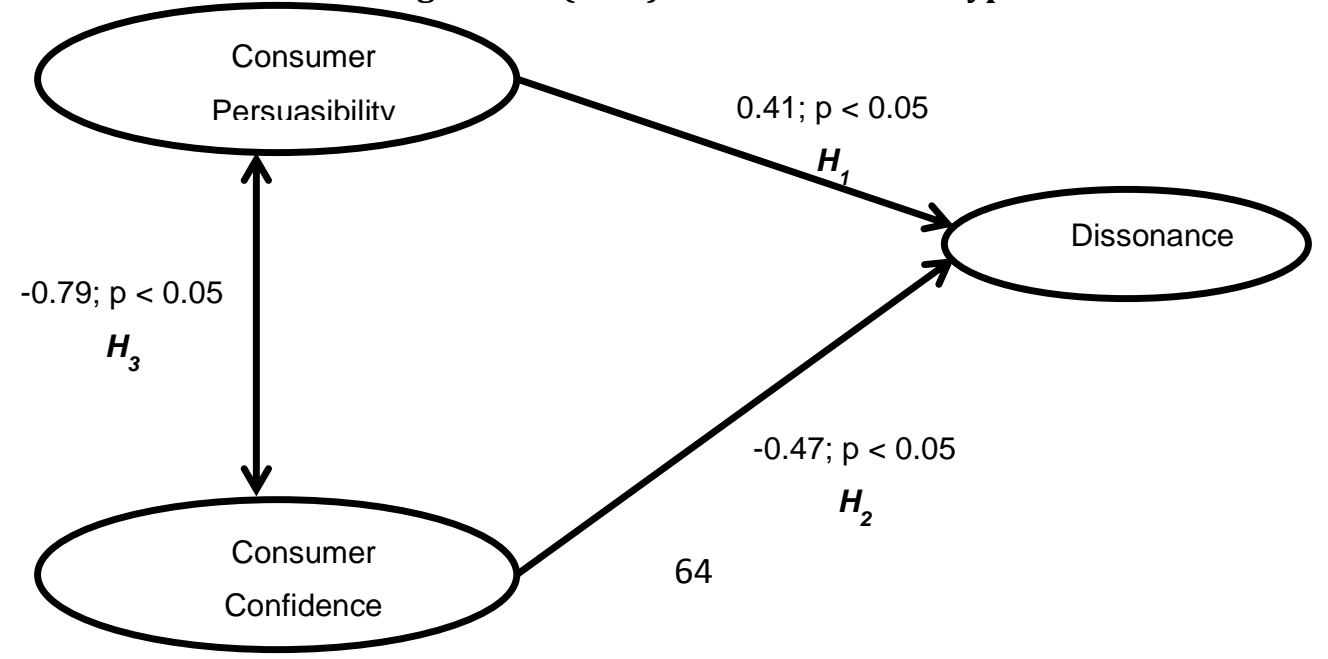


Table 3 depicts the standardized regression coefficients estimated by SEM analyses using AMOS.

\begin{tabular}{lccc} 
Table 3: Standardized regression coefficients of the variables & & \\
\hline $\begin{array}{l}\text { Dimension } \\
\text { Dissonance }\end{array}$ & Estimate & S.E. & p \\
\hline $\begin{array}{l}\text { Consumer persuasibility } \\
\text { Consumer confidence }\end{array}$ & 0.434 & 0.112 & $0.000^{*}$ \\
$\begin{array}{l}\text { Consumer Confidence } \\
\text { Consumer persuasibility }\end{array}$ & -0.538 & 0.131 & $0.000^{*}$ \\
\hline
\end{tabular}

$* \mathrm{p}<0.01$

The structural model indicates that there is a significant, moderate relationship between consumer persuasibility and dissonance at the $1 \%$ level of significance. Hence, Hypothesis 1 may be accepted. The implication is that the higher the level of consumer persuasibility during the decision makes process, the higher the level of dissonance experienced. Furthermore, there is a significant but inverse relationship between consumer confidence in the decision making process and dissonance experienced at the $1 \%$ level of significance. Therefore, Hypothesis 2 may be accepted. As anticipated, the results imply that the higher the level of consumer confidence in the decision makes process, the lower the degree of dissonance experienced. In addition, consumer confidence and consumer persuasibility are significantly and inversely related as they influence the magnitude of dissonance experienced $(p=0.000)$. Hence, Hypothesis 3 may be accepted. The implication is that as consumer confidence in the decision-making process increases, their potential for persuasion decreases thereby decreasing dissonance experienced and vice versa. As previously indicated, a substantial amount of variation in the model is explained by the relationships depicted in the model. The model accounts for $67.1 \%$ of the variance thereby providing further support for the model's fit.

Discussion: Consumers differ in their susceptibility to persuasion. The findings of the study reflect a significant relationship between consumer persuasibility, especially by the salesperson, and dissonance experienced. Sweeney et al. (2000) refer to the consumer's feelings that he/she may have been influenced against his/her own beliefs by the salesperson as 'concern over the deal'. The results of the current study correspond with Engel's (1963) belief that consumers who are more easily persuaded will be highly dissonant after the purchase. In the current study, like that of Engel's (1963), consumers reported that they had been talked into buying a motor vehicle that they did not like and for the price that they did not want to pay. Similarly, Bell (1967) found that all consumers may not be cognitively dissonant. Instead, dissonance may be influenced by the personality type of the consumer. However, Bell (1967) found no association between persuasibility and dissonance and attributed this to the customer's self-confidence which influences persuasibility as well as dissonance.

In this study, structural equation modeling also confirmed a significant, inverse relationship between the level of confidence of the motor vehicle buyer during the decision-making process and dissonance experienced. In other words, the higher the level of consumer confidence during the decision-making process, the lower the level of experienced dissonance. Similar findings were obtained by other researchers (Bell, 1967; Cheng \& Hsu, 2012). This is related to the findings of several researchers that consumer confidence is specifically related to consumer information search as more confident consumers are willing to engage in extensive search especially for high-end purchases (Bearden et al., 2001; Loibl et al., 2009) and to evaluate multiple alternatives (Reed et al., 2012). Similar findings were reported by Wells and Prensky (1996) in terms of a positive relationship between high consumer confidence and high information strategy although Kiel and Layton (1981) reported the converse. The results of the current study are congruent with that of Bell (1967) who found that consumers would be more dissonant, the more uneasy they were about the purchase decision and, the more they wondered if they had made the correct decision or received the same kind of deal that other consumers had received. 
The results of the current study also reflect a significant, inverse relationship between consumer confidence and consumer persuasibility. As expected, as the consumer's level of confidence in the decision-making process increases, the potential to be persuaded by the salesperson during the purchase decreases. Likewise, Bell (1967) deduced from his study that a consumer's self-confidence has an unusual effect on persuasibility. Those most confident and those least confident in their motor vehicle buying ability are the most difficult to persuade and those who are moderately confident are most easily persuaded (Bell, 1967). Consumers who are high in self-confidence are difficult to influence because they have experience in making suitable decisions and believe in their own judgments (Loibl et al., 2009) and rely less on decision aid (Whitecotton, 1996 cited in Woolley, 2007). Lee and Dry (2006) deduced that confidence is influenced both by frequency and accuracy of the advice whilst Koller and Salzberger (2012) found that confidence is influenced by enthusiasm for information. Newman and Staelin (1971) found that consumers who hold high confidence in their own ability to assess the product reported significantly longer information search than those who believed that they had to trust the judgement and advice of others. Consumers who are low in self-confidence are difficult to persuade because their insecure self-esteem triggers them to react defensively against any attempts to influence them (Bell, 1967).

Other researchers have also assessed susceptibility to persuasion based on the nature of the message and have concluded that two-sided message are superior in terms of its cognitive effect on the recipient (consumer) (Crowley \& Hoyer, 1994; Koller \& Salzberger, 2012; Nadeem, 2007; Soutar \& Sweeney, 2003; Stanchi, 2013) although Sanaktekin and Sunar (2008) believed that its effectiveness depended on how informed the recipients (consumers) were before the message and Walsh et al. (2007) emphasized the importance of cognitive clarity. Greenwald (1969) maintains that self-confidence should not increase spreading apart in high-conflict decisions because an uncertain consumer who lacks justification for a decision seeks additional justification whereas a confident person need not justify a decision. Furthermore, consumer confidence and persuasibility are inversely related in their impact on dissonance. It can therefore, be concluded from the current study that dissonance arousal is a direct function of a high level of consumer persuasibility and is inversely related to consumer confidence in the decision-making process. Furthermore, consumer confidence and consumer persuasibility are significantly but inversely related as they influence the magnitude of dissonance experienced.

\section{Conclusion and Recommendations}

Consumers differ in their susceptibility to persuasion; however, whilst personality cannot be changed by marketing practitioners, salespersons and strategists, every attempt can be made to ensure that postpurchase dissonance is reduced by designing effective two-sided messages as they are superior in terms of their cognitive effect and their balanced perspective make them positively more persuasive. Especially before a high-end purchase, the frequency and accuracy of advice and cognitive clarity is imperative in reducing post-purchase dissonance. It is also necessary for the salesperson and decision aid to understand the consumer's needs lifestyle and purchasing power and, dealerships need to design certain advertisements for recent purchasers to bolster confidence and reinforce the correctness of the purchase decision. Merging such features into the marketing and sales strategies will increase the level of consumer confidence thereby reducing the level of dissonance experienced. This is imperative as a strong interdependence exists between consumer persuasibility, consumer confidence and post-purchase dissonance.

Limitations of the study: This study focuses on the impact of consumer confidence and consumer persuasibility on dissonance and develops, validates and applies an instrument to these constructs to the exclusion of the numerous other constructs that have the potential to influence post-purchase dissonance. It would be valuable to design similar tools to assess the impact of the other dimensions, especially with regards to high-end purchases. 


\section{References}

Aronson, E. (1968). Dissonance theory: Progress and problems in theories of cognitive consistency: A Sourcebook, Edited by R. Abelson, et al. Chicago: Rand McNally, 5-27.

Aronson, E. (1992). The return of the repressed: Dissonance theory makes a comeback. Psychological Inquiry, 3(4), 303-311.

Bearden, W. O., Hardesty, D. M. \& Rose, R. L. (2001). Consumer self-confidence: Refinements in conceptualization and measurement. Journal of Consumer Research, 28, 121-134.

Bell, G. D. (1967). The automobile buyer after the purchase. Journal of Marketing, 31, 12-16.

Bollen, K. A. (1989). Structural Equations with Latent Variables, New York: John Wiley and Sons.

Browne, M. W. \& Cudeck, R. (1993). Alternative ways of assessing model fit, in K.A. Bollen \& J.S. Long (Eds.), Testing structural equation models (pp. 136-162). Newsbury Park, CA: Sage.

Byrne, B. M. (1994). Structural equation modeling with EQS and EQS/Windows, Thousand Oaks, CA: Sage Publications.

Cheng, P. \& Hsu, P. (2012). Cognitive dissonance theory and the certification examination: The role of responsibility. Social Behavior and Personality, 40(7), 1103-1112.

Clark, R. A., Goldsmith, R. E. \& Goldsmith, E. B. (2008). Market mavenism and consumer self-confidence. Journal of Consumer Behaviour, 7, 239-248.

Crowley, A. E. \& Hoyer, W. D. (1994). An integrative framework for understanding two-sided persuasion. Journal of Consumer Research, 20, 561-574.

Cummings, W. H. \& Venkatesan, M. (1976). Cognitive dissonance and consumer behaviour: A review of the evidence. Journal of Marketing Research, 13, 303-308.

Ehrlich, D., Guttman, I., Schonbach, P. \& Mills, J. (1957). Post decision exposure to relevant information. Journal of Abnormal and Social Psychology, 54, 98-102.

Elliot, A. J. \& Devine, L. G. (1994). On the motivational nature of cognitive dissonance: Dissonance as psychological discomfort. Journal of Personality and Social Psychology, 67(3), 382-394.

Engel, J. F. (1963). Are Automobile purchasers dissonant consumers? Journal of Marketing, 29(34).

Engel, J. F. \& Blackwell, R. D. (1982). Consumer Behavior (4th Ed), Chicago: The Dryden Press.

Festinger, L. (1957). A theory of cognitive dissonance, Evanston, IL: Row, Peterson.

Festinger, L. \& Carlsmith, J. M. (1959). Cognitive consequences of forced compliance. Journal of Abnormal and Social Psychology, 58, 203-211.

Gawronski, B. (2012). Back to the future of dissonance theory: Cognitive consistency as a core motive. Social Cognition, 30(6), 652-668.

George, B. P. \& Edward, M. (2009). Cognitive dissonance and purchase involvement in the consumer behaviour context. The IUP Journal of Marketing Management, 8(3-4), 7-24.

Goethals, G. R. (1992). Dissonance and self-justification. Psychological Inquiry, 3(4), 327-329.

Greenwald, H. J. (1969). Dissonance and relative versus absolute attractiveness of decision alternatives. Journal of Personality and Social Psychology, 11, 328-333.

Herman, S. (2006). Cognitive dissonance. Chemical Reaction. Global Cosmetic Industry, 174(1), 58-60.

Hoshino-Browne, E. (2012). Cultural variations in motivation for cognitive consistency: Influences of selfsystems of cognitive dissonance. Social and Personality Psychology Compass, 6(2), 126-141.

Hu, L. \& Bentler, P. M. (1999). Cut-off criteria for fit indexes in covariance structure analysis: Conventional criteria versus new alternatives. Structural Equation Modeling, 6(1), 1-55.

Jarcho, J. M., Berkman, E. T. \& Lieberman, M. D. (2011). The neural basis of rationalization: Cognitive dissonance reduction during decision-making. SCAN, 6, 460-467.

Kassarjian, H. H. \& Cohen, J. B. (1965). Cognitive dissonance and consumer behaviour. California Management Review, 8, 55-64.

Keng, C. \& Liao, T. (2009). Consequences of post purchase dissonance: The mediating role of an external information search. Social Behavior and Personality, 37(10), 1327-1340.

Kiel, G. C. \& Layton, R. A. (1981). Dimensions of consumer information seeking behaviour. Journal of Marketing Research, 18(2), 233-239.

Kim, Y. (2011). Application of the cognitive dissonance theory to the service industry. Services Marketing Quarterly, 32, 96-112. 
Koller, M. \& Salzberger, T. (2012). Heterogeneous development of cognitive dissonance over time and its effect on satisfaction and loyalty. Journal of Customer Behaviour, 11(3), 261-280.

Kunreuther, H., Meyer, R., Zeskhauser, R., Slovic, P., Schwartz, B., Schade, C., Luce, M. F., Lippman, S., Krantz, D., Kahn, L. \& Hogart, R. (2002). High stakes decision making: Normative, descriptive and prescriptive considerations. Marketing Letters, 13(3), 259-268.

Lee, M. D. \& Dry, M. J. (2006). Decision making and confidence given uncertain advice. Cognitive Science, 30, 1081-1095.

Loibl, C., Cho, S. H., Diermann, F. \& Batte, M. T. (2009). Consumer self-confidence in searching for information. The Journal of Consumer Affairs, 43(1), 26-55.

Markin, Jr. R. J. (1974). Consumer Behaviour: A Cognitive Orientation, New York: Macmillan Publishing Co., Inc.

Nadeem, M. M. (2007). Post-purchase dissonance: The wisdom of the 'repeat' purchases. The Journal of Global Business Issues, 1(2), 183-193.

Newman, J. \& Staelin, R. (1971). Multivariate analysis of differences in buyer decision time. Journal of Marketing Research, 8, 192-198.

Nolan, J. \& Nail, P. (2014). Further evidence that individuals with a high preference for consistency are more susceptible to cognitive dissonance. PSI CHI Journal of Psychological Research. The International Honor Society in Psychology, 19(4), 214-219.

Petty, R. E., Unnava, R. \& Stratman, A. J. (1991). Theories of attitude change. In T.S. Robertson \& H.H. Kassarjian (Eds). Handbook of Consumer Behavior. pp. 241- 280. Engelwood Cliffs, New Jersey: Prentice-Hall.

Reed, A. E., Mikels, J. A. \& Löckenhoff, C. E. (2012). Choosing with confidence: Self-efficacy and preferences for choice. Judgment and Decision Making, 7(2), 173-180.

Sanaktekin, Ö. H. \& Sunar, D. (2008). Persuasion and relational versus personal bases of self-esteem: Does the message need to be one- or two-sided? Social Behavior and Personality, 36(10), 1315-1332.

Soutar, G. N. \& Sweeney, J. C. (2003). Are there cognitive dissonance segments? Australian Journal of Management, 28(3), 227-249.

Stanchi, K. (2013). What cognitive dissonance tells us about tone in persuasion. Journal of Law and Policy, 22(1), 93-133.

Stuart, O. D. (1984). A note of the measurement quantification and use of consumer confidence. Journal of Economic Psychology, 5(2), 128-138.

Sweeney, J. C., Hausknecht, D. \& Soutar, G. N. (2000). Cognitive dissonance after purchase: A multidimensional scale. Psychology and Marketing, 17(5), 369-385.

Szmigin, I., Carrigan, M. \& McEachern, M. (2008). Flexibility, dissonance and the conscious consumer. European Advances in Consumer Research, 8, 379-380.

Tabor, E. B. (2005). Book Review. The power of persuasion: How we're bought and sold. Psychiatric Services, $56(5), 614$.

Ullman, J. B. (2001). Structural equation modeling, In B.G. Tabachnick \& L.S. Fidell (2001). Using Multivariate Statistics (4th Ed; pp 653- 771). Needham Heights, MA: Allyn \& Bacon.

Walsh, G., Hennig-Thurau, T. \& Mitchell, V. (2007). Consumer confusion proneness: scale development, validation, and application. Journal of Marketing Management, 23(7-8), 697-721.

Wells, W. D. \& Prensky, D. (1996). Consumer Behavior. New York: John Wiley.

Wicklund, R. A. \& Brehm, J. W. (1976). Perspectives on cognitive dissonance. Hillsdale, N.J.: Lawrence Erlbaum Associates, Inc.

Woolley, D. J. (2007). The influence of decision commitment and decision guidance on directing decision aid recommendations. Academy of Information and Management Sciences Journal, 10(2), 39-55.

Zajonc, R. B. (1960). The concepts of balance, congruity and dissonance. Public Opinion Quarterly, 24, 280296. 